Check for updates

Cite this: RSC Adv., 2017, 7, 46948

Received 1st September 2017

Accepted 29th September 2017

DOI: $10.1039 / c 7 r a 09728 j$

rsc.li/rsc-advances

\section{First assessment on degradability of sodium $p$ - perfluorous nonenoxybenzene sulfonate (OBS), a high volume alternative to perfluorooctane sulfonate in fire-fighting foams and oil production agents in China $\uparrow$}

\author{
Yixiang Bao, ${ }^{a}$ Yingxi Qu, ${ }^{a}$ Jun Huang, (D) *a Giovanni Cagnetta, ${ }^{a}$ Gang Yu ${ }^{a}$ \\ and Roland Weber ${ }^{b}$
}

Sodium $p$-perfluorous nonenoxybenzene sulfonate (OBS) is widely used in China as fire-fighting foam coformulant and oil production agent, because it is an economical alternative to perfluorooctane sulfonate (PFOS), classified as persistent organic pollutant by the Stockholm Convention. Such chemical very likely possesses toxicological and bioaccumulative characteristics that are similar to PFOS and many other perfluorinated compounds. However, in this first report we demonstrate that OBS, in spite of its nonreadily biodegradability, can be decomposed by $\mathrm{UV} / \mathrm{H}_{2} \mathrm{O}_{2}$ or even sole $\mathrm{UV}(254 \mathrm{~nm}$ ) system (contrary to PFOS). More than $96 \%$ OBS is degraded in aqueous solution within 20 minutes by both methods thanks to its peculiar molecular structure. Yet, after $2 \mathrm{~h}$ reaction $U V / \mathrm{H}_{2} \mathrm{O}_{2}$ gives $99 \%$ sulfate recovery, while in UV system only $61 \%$ sulfate is detected; fluoride recovery was less than $16 \%$ for both treatments. Such results, corroborated by intermediate identification, highlight that $\mathrm{UV} / \mathrm{H}_{2} \mathrm{O}_{2}$ system can effectively destroy the OBS sulfonated aromatic moiety. On contrary, it remains intact in several products of the UV treatment, raising a concern on their potential toxicity. Such results demonstrate OBS better degradability and treatability, compared to other perfluorinated chemicals, and suggest that it might be biodegraded on long term. Moreover, these findings may be of help for a more environmentally friendly eco-design of other fluorinated alternatives.

\section{Introduction}

Perfluorooctane sulfonate (PFOS) is an environmental pollutant and belongs to the chemical group of perfluoroalkyl substances. PFOS has been widely used for various commercial applications for more than 50 years. ${ }^{1}$ It has been found to be persistent, ${ }^{2}$ toxic and bioaccumulative ${ }^{3}$ in the environment, and has been detected worldwide in the environment, as well as in human blood and liver samples. ${ }^{4,5}$ Due to these findings, the phase-out of PFOS has been initiated since 2000. Similarly, an increasing number of other long-chain fluorinated chemicals are being phased out. ${ }^{6}$ In May 2009, PFOS, its salts and related precursor substances produced from perfluorooctane sulfonyl fluoride

${ }^{a}$ State Key Joint Laboratory of Environment Simulation and Pollution Control (SKJLESPC), Beijing Key Laboratory for Emerging Organic Contaminants Control (BKLEOC), School of Environment, POPs Research Center, Tsinghua University, Beijing, 100084, China. E-mail: huangjun@tsinghua.edu.cn; Fax: +86 106279 4006; Tel: +861062792598

${ }^{b}$ POPs Environmental Consulting, Lindenfirststr. 23, D-73527 SchwäbischGmünd, Germany

$\dagger$ Electronic supplementary information (ESI) available. See DOI: $10.1039 / \mathrm{c} 7 \mathrm{ra09728j}$ were listed under the Annex B of Stockholm Convention as persistent organic pollutants. Therefore, as a contracting party of Stockholm Convention, China is working on the control and phase out of these chemicals.

The majority of alternatives currently available on the market are still organofluorine chemicals. As indicated in the Madrid Statement, also these alternative perfluoroalkyl substances are of concern due to their persistence (or that of their degradation products) combined with lack of detailed toxicity assessment. ${ }^{7}$ In fact, almost all these chemicals have similar toxicity and tendency to bioaccumulate in living tissues. ${ }^{8}$ Also, some short chain alternatives ( $<6$ carbon atoms), claimed to be safer than long chain homologues, have even been found to be bioaccumulative and toxic, as well as persistent. ${ }^{9-12}$

Sodium $p$-perfluorous nonenoxybenzene sulfonate (OBS, $\mathrm{C}_{9} \mathrm{~F}_{17} \mathrm{OC}_{6} \mathrm{H}_{4} \mathrm{SO}_{3} \mathrm{Na}$, CAS no. 70829-87-7, Fig. 1) belongs to the group of PFASs with an aromatic moiety. As a cost-effective surfactant, it is widely used in China as co-formulant of fluoroprotein fire-fighting foams, oil production agents, and photographic materials. ${ }^{13}$ There are several manufacturers of OBS in China, with an estimated total production capacity of about $3500 \mathrm{t}$ per year. Also in recent years, some efforts were put 


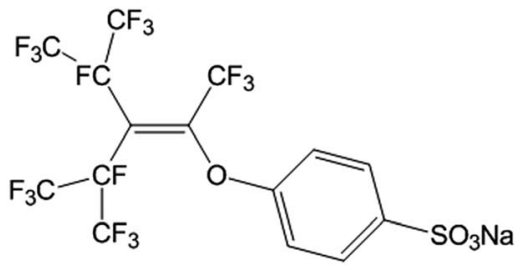

Fig. 1 Chemical structure of OBS.

to develop synthesis method of OBS and its derivatives. ${ }^{\mathbf{1 4 , 1 5}}$ With regard to its pollution potential, OBS has been recently detected in water samples from urban wastewater treatment plant and local rivers in oil-field area of North China. ${ }^{\mathbf{1 6}}$ This fact raises a serious concern about its possible further spread in the environment and, consequently, on risk for humans, because OBS is very likely as toxic and persistent as the large majority of perfluoroalkyl chemicals.

A key issue to predict OBS environmental behavior is its degradability, caused by both biotic and abiotic processes. But, there is a lack of information on this aspect. Still, OBS molecule presents some weak points (i.e. a double bond, an etheric bridge, and a phenylsulfonate moiety) that may cause lower stability. A study on this aspect would be helpful not only to collect clues on possible fate of OBS into the environment, but also to estimate its treatability in water to prevent point source emissions. As a matter of fact, such studies were already conducted on other fluorocompounds. Schröder and Meesters ${ }^{\mathbf{1 7}}$ have investigated the stability of several anionic and non-ionic fluorinated surfactants under conditions of advanced oxidation processes (AOPs), including ozone $\left(\mathrm{O}_{3}\right), \mathrm{O}_{3} / \mathrm{UV}, \mathrm{O}_{3} / \mathrm{H}_{2} \mathrm{O}_{2}$, and $\mathrm{H}_{2} \mathrm{O}_{2} / \mathrm{Fe}^{2+}$. The results provided insights for an improved treatability of these pollutants. Quinete et al. ${ }^{18}$ tested both biodegradability and AOP stability of several emerging perfluorinated surfactant substitutes (i.e. fluoroaliphatic esters, the fluorosurfactant Zonyl, perfluorobutane sulfonate, and 10(trifluoromethoxy)decane-1-sulfonate). Biodegradability tests for these all fluorosurfactants using the manometric respirometry method (Oxi-Top) yielded the same result of nonreadily biodegradability. In comparison, the AOP stability of NOVEC FC-4430 and NOVEC FC-4432 (two fluorochemicals employed as coating additives) was significantly lower than that of perfluorobutane sulfonate. Also the authors found that the more stable alternatives under AOPs showed stronger recalcitrance to biological treatment. Therefore, AOP stability can be a promising indicator of biological recalcitrance or treatability of fluorosurfactants.

In our previous studies, we successfully investigated the AOP stability of two fluorosurfactants used as PFOS-alternatives, i.e. F-53B $\left(\mathrm{Cl}\left(\mathrm{CF}_{2}\right)_{6} \mathrm{O}\left(\mathrm{CF}_{2}\right)_{2} \mathrm{SO}_{3}{ }^{-\cdot} \mathrm{K}^{+}\right.$, CAS no. 73606-19-6) and $6: 2$ FTS-K $\left(\mathrm{F}\left(\mathrm{CF}_{2}\right)_{6} \mathrm{CH}_{2} \mathrm{CH}_{2} \mathrm{SO}_{3}{ }^{-\cdot} \mathrm{K}^{+}\right.$, CAS no. 59587-38-1). F-53B was found to be as stable as PFOS potassium under all AOPs conditions, while 6:2 FTS-K was proven to be more degradable. ${ }^{19,20}$ Following the same methodology, the stability of OBS under $\mathrm{UV} / \mathrm{H}_{2} \mathrm{O}_{2}$, which has high $\mathrm{OH}$ radical productivity, is assessed, and main intermediates and products are also identified. In comparison, OBS degradation by UV irradiation in aqueous solution is also investigated, as well as degradation products and photochemical degradation mechanisms. These data are important for the evaluation of OBS environmental fate and to estimate the pollution potential of this large volume PFOS-alternative mainly produced and widely used in China.

\section{Materials and methods}

\subsection{Chemicals}

OBS was purchased from $3 \mathrm{~F}$ Corporation (Shanghai, China). $\mathrm{H}_{2} \mathrm{O}_{2}$ (30\%, Sinopharm Chemical Reagent) was used in AOP treatment tests. Tert-butanol $\left(\mathrm{C}_{4} \mathrm{H}_{10} \mathrm{O}\right.$, TBA, Sinopharm Chemical Reagent Co.), sorbic acid $\left(\mathrm{C}_{6} \mathrm{H}_{8} \mathrm{O}_{2}\right.$, SA, AccuStandard), and 1,4-benzoquinone $\left(\mathrm{C}_{6} \mathrm{H}_{4} \mathrm{O}_{2}, \mathrm{BQ}, 99 \%\right.$, J\&K Scientific) were used as scavengers. Trifluoroacetic acid (TFA, LC-MS grade, CNW Technologies), phenol sulfonic acid $\left(\mathrm{C}_{6} \mathrm{H}_{5} \mathrm{O}_{4} \mathrm{SNa}\right.$, PSA, $>98.0 \%$, TCI (Shanghai) Development Co.), methanol $\left(\mathrm{CH}_{3} \mathrm{OH}\right.$, HPLC grade, Avantor Performance Materials), sodium dihydrogen phosphate $\left(\mathrm{NaH}_{2} \mathrm{PO}_{4} \cdot 2 \mathrm{H}_{2} \mathrm{O}\right.$, Modern Oriental (Beijing) Technology Development Co.), and ammonium acetate $\left(\mathrm{NH}_{4} \mathrm{Ac}\right.$, Sinopharm Chemical Reagent Co.) were used for identification/ quantification of the degradation products. Aqueous solutions were prepared using ultrapure water $(18.2 \mathrm{M} \Omega \mathrm{cm}$, Millipore, USA).

\subsection{Experimental methods}

The readily-biodegradability of OBS was assessed by the Closed Bottle Test (CBT) method according to the guidelines for testing of chemicals (method 301 D) of the Organization for Economic Cooperation and Development (OECD) (the detailed procedure is described in ESI, Section S1 $\dagger$ ). The secondary effluent from a municipal wastewater treatment plant was adopted as microbial inoculum in all tests. Duplicate measurements for OBS, reference substance and blank were performed.

The OBS solution used in all abiotic degradation experiments (namely, under AOP conditions) were prepared with concentration of $0.16 \mathrm{mM}$ in ultrapure water. The UV irradiation experiment was performed in quartz glass tube containing $300 \mathrm{~mL}$ OBS solution in a photochemical reactor (RPR200, Southern New England Ultraviolet (Rayonet) Co., USA). The quartz tube was placed in the middle of the reactor $(25 \mathrm{~cm}$ diameter) and surrounded by 4 of UV lamps with wavelength of $253.7 \mathrm{~nm}$ (with approximate intensity of $1.6 \times 10^{16}$ photons s$^{-1}$ $\mathrm{cm}^{-3}$ ) at room temperature (around $20^{\circ} \mathrm{C}$ ). The photochemical reactor was operated 5 minutes before the OBS solution was poured into the quartz tube. The $\mathrm{UV} / \mathrm{H}_{2} \mathrm{O}_{2}$ experiments were carried out by adding different volumes of $30 \% \mathrm{H}_{2} \mathrm{O}_{2}$ solution in $300 \mathrm{~mL}$ OBS solution under the aforementioned UV irradiation conditions. Reaction medium was magnetically stirred at $200 \mathrm{rpm}$. Samples $(3 \mathrm{~mL})$ were withdrawn from the reaction solution at specified times.

\subsection{Instrumental analysis}

Fluorides and sulfates were quantified by ion chromatography (Dionex ICS 2000, USA). OBS was determined by high- 
performance liquid chromatography (HPLC, LC-20AT, Shimadzu, Japan) equipped with UV/Vis detector at $275 \mathrm{~nm}$ (SPD20A, Shimadzu, Japan). The mobile phase was methanol : $0.02 \mathrm{M}$ dihydrogen phosphate buffer solution $(8: 2$,

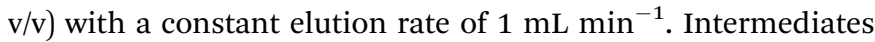
and by-products were identified by liquid chromatography (LC, DIONEX UltiMate 3000, USA) equipped with XBridge C18 column $(3.0 \times 150 \mathrm{~mm}, 3.5 \mu \mathrm{m}$, Waters $)$, followed by a tandem of two time of flight mass spectrometers (TOFMS, micrOTOF-Q III BRUKER, Germany) The LC column temperature was $30^{\circ} \mathrm{C}$, flow rate of the mobile phase $\left(10 \mathrm{mM} \mathrm{NH}_{4} \mathrm{Ac}\right.$ aqueous solution (phase A) and methanol (phase B)) was kept at $0.3 \mathrm{~mL} \mathrm{~min}^{-1}$. The linear gradient was set to $1: 9 \mathrm{~A}: \mathrm{B}$ from 0 to $15 \mathrm{~min}, 9: 1$ A : B from 15 to $25 \mathrm{~min}$ and 1 : $9 \mathrm{~A}$ : B from 25 to $32 \mathrm{~min}$. The TOFMS was operated in electrospray ionization (ESI) negative ion mode, with spray voltage of $3.5 \mathrm{kV}$ and mass scan range of 100-1000. The mass accuracy was corrected by infusion of sodium formate aqueous solution. LC (DIONEX UltiMate 3000, USA) with tandem of 2-stage mass spectrometer (MS/MS, API 3200, AB SCIEX, USA) was used to quantify the TFA and PSA generated during the degradation of OBS. The same conditions of LC were used for the (semi)quantification of the products. Negative electrospray ionization mode with multiple reaction monitoring (MRM) was used for MS/MS. Ionization voltage was $4.5 \mathrm{kV}$ and temperature of $450{ }^{\circ} \mathrm{C}$. The pressures for curtain gas, collision gas, ion source gas 1 and ion source gas 2 were set to 10, 5, 60, and $40 \mathrm{psi}$, respectively. Optimized parameters for quantification of PSA and TFA are summarized in Table S1. $\uparrow$ A UV-vis spectrophotometer (DR 5000, Hatch, USA) was used to detect the absorption band of the various solutions. Electron spin resonance spectrometer (ESR, JES-FA200, JEOL, Japan) equipped with an USHIO Optical MoluleX as light source was used to detect radicals generated during the reaction.

\section{Results and discussion}

\subsection{Biotic degradation}

The biochemical oxygen demand (BOD) evaluated by 28 day tests (referred to that of the blank) of OBS and a reference substrate (sodium benzoate) is shown in Table S2. $\dagger$ The biodegradation percentage of OBS (calculated as ratio of BOD to theoretical oxygen demand (ThOD, $0.599 \mathrm{mg} \mathrm{mg}^{-1}$ for OBS), and shown in Table S3†) demonstrated that OBS caused irrelevant oxygen depletion during the test. On contrary, the reference substance was significantly biodegraded in the same period. These findings strongly suggest that the fluorinated compound was not involved in any short term biological process. In other words, it is non-readily biodegraded. It clearly implies a significant recalcitrance of OBS to biodegradation and its potential persistence in the natural environment. Hence, the present study mainly focuses on abiotic degradation, which can provide clues also on long term biological degradation.

\subsection{Abiotic degradation}

Unlike PFOS or other perfluoroalkyl substances, which are highly resistant to AOPs, OBS can be readily decomposed in both UV and
$\mathrm{UV} / \mathrm{H}_{2} \mathrm{O}_{2}$ systems (Fig. 2a). More than $96 \%$ OBS parent molecules were degraded under the tested conditions within 20 min. Early degradation stage demonstrates in a straightforward manner that $10 \mathrm{mM} \mathrm{H} \mathrm{H}_{2} \mathrm{O}_{2}$ dosage (62.5 $\mathrm{H}_{2} \mathrm{O}_{2}$ /OBS molar ratio) induces the fastest OBS depletion rate (Fig. 2b). Higher dosages, however, determine a decrease in degradation rate, caused by selfconsumption of generated $\mathrm{OH}$ radicals (eqn (1)). OBS was still detectable after 120 min under UV irradiation. The degradation processes fitted well with pseudo-first order kinetics (Fig. S1 $\dagger$ ). The test series confirmed that the optimal dose for $\mathrm{H}_{2} \mathrm{O}_{2}$ is $10 \mathrm{mM}$. In this case, the related fitting calculation showed a degradation rate constant of $k=0.2597 \pm 0.0074 \mathrm{~min}^{-1}$, which is 1.6 times higher than that in the UV system without $\mathrm{H}_{2} \mathrm{O}_{2} \quad(k=0.1695 \pm$ $0.0127 \mathrm{~min}^{-1}$ ).

$$
\mathrm{H}_{2} \mathrm{O}_{2}+2 \mathrm{OH}^{\cdot}=2 \mathrm{H}_{2} \mathrm{O}+\mathrm{O}_{2}
$$

Fluorine ion recovery during the degradation of OBS is important to determine the mineralization degree of its perfluorinated moiety. Under sole UV light, $14.8 \%$ of total fluorine content of the OBS molecule was found in solution as fluorides, while in $\mathrm{UV} / \mathrm{H}_{2} \mathrm{O}_{2}$ system fluoride recovery was $16.1 \%$. This shows that the perfluorinated chain is only partly degraded. On the other hand, release of sulfates in the reaction medium indicates that the
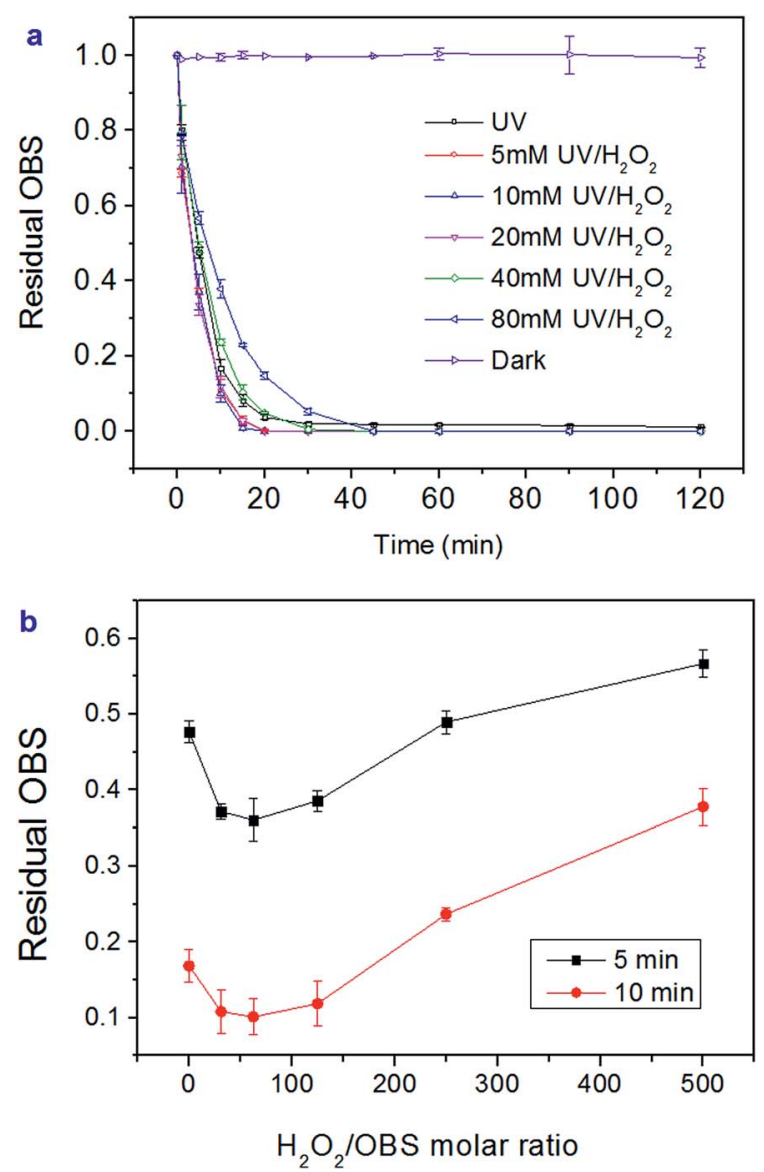

Fig. 2 Residual OBS in UV and UV/ $\mathrm{H}_{2} \mathrm{O}_{2}$ system correlated with irradiation time (a) and $\mathrm{H}_{2} \mathrm{O}_{2} / \mathrm{OBS}$ molar ratio for 5 and 10 min irradiation (b). 


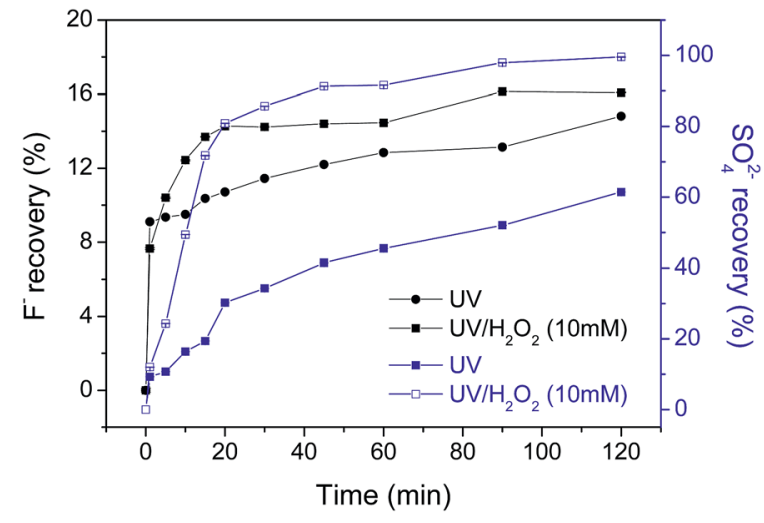

Fig. 3 Recovery ratio of fluorine ion and sulfate ion for OBS in UV and $\mathrm{UV} / \mathrm{H}_{2} \mathrm{O}_{2}$ system (error is $\leq 0.05$ for all data).

aromatic moiety undergoes degradation. In fact, more than $99 \%$ and $61 \%$ sulfate is found in solution for $\mathrm{UV} / \mathrm{H}_{2} \mathrm{O}_{2}$ and UV tests, respectively. Such remarkable difference indicates that the benzene sulfonate moiety is effectively destroyed by $\mathrm{UV} / \mathrm{H}_{2} \mathrm{O}_{2}$, but only partially mineralized under UV irradiation (Fig. 3).

\subsection{Degradation products and proposed pathway of OBS degradation in $\mathrm{UV} / \mathrm{H}_{2} \mathrm{O}_{2}$ system}

OBS degradation intermediates were identified by liquid chromatography with MS detector (LC-TOFMS). A base peak chromatogram (BPC-All MS) model was adopted to determine the products with prominent peak intensity. The blank sample (ultrapure water) was used to exclude unknown substances from the base peak chromatogram. In total, 7 stable degradation products were detected after $2 \mathrm{~h}$ reaction. The compound spectra and the assigned corresponding structures are showed in Fig. $\mathrm{S} 2 \dagger$ and hereafter identified by their chemical formula: $\mathrm{C}_{10} \mathrm{H}_{2} \mathrm{~F}_{15} \mathrm{O}_{5}{ }^{-}(\mathrm{m} / \mathrm{z}=486.9), \mathrm{C}_{7} \mathrm{HF}_{14} \mathrm{O}^{-}(\mathrm{m} / \mathrm{z}=366.9), \mathrm{C}_{7} \mathrm{HF}_{12} \mathrm{O}_{3}{ }^{-}$ $(m / z=360.9), \mathrm{C}_{4} \mathrm{~F}_{7} \mathrm{O}_{2}{ }^{-}(m / z=212.9), \mathrm{C}_{4} \mathrm{HF}_{6} \mathrm{O}_{3}{ }^{-}(\mathrm{m} / \mathrm{z}=210.9)$, $\mathrm{C}_{3} \mathrm{HF}_{6} \mathrm{O}_{2}{ }^{-}(m / z=182.9)$, and $\mathrm{C}_{2} \mathrm{~F}_{3} \mathrm{O}_{2}{ }^{-}$(i.e. TFA, $\left.m / z=112.9\right)$. In addition, 6 intermediates were detected (Fig. $\mathrm{S} 2 \dagger$ ): $\mathrm{C}_{15} \mathrm{H}_{6} \mathrm{~F}_{17} \mathrm{O}_{7} \mathrm{~S}^{-}(m / z=652.9), \mathrm{C}_{15} \mathrm{H}_{4} \mathrm{~F}_{17} \mathrm{O}_{5} \mathrm{~S}^{-} \quad(m / z=618.9)$, $\mathrm{C}_{15} \mathrm{H}_{6} \mathrm{~F}_{15} \mathrm{O}_{6} \mathrm{~S}^{-}(\mathrm{m} / \mathrm{z}=598.9), \mathrm{C}_{15} \mathrm{H}_{6} \mathrm{~F}_{15} \mathrm{O}_{7} \mathrm{~S}^{-} \quad(m / z=614.9)$, $\mathrm{C}_{14} \mathrm{H}_{5} \mathrm{~F}_{14} \mathrm{O}_{7} \mathrm{~S}^{-}(\mathrm{m} / \mathrm{z}=582.5)$, and $\mathrm{C}_{9} \mathrm{~F}_{17} \mathrm{O}^{-}(\mathrm{m} / \mathrm{z}=446.9)$.

Based on the identified products above, a possible degradation pathway of OBS under $\mathrm{UV} / \mathrm{H}_{2} \mathrm{O}_{2}$ (dominated by hydroxyl radical) is proposed (Fig. 4). It is well-known that $\mathrm{OH}$ radical reacts with organic compounds in aqueous solution by 3 mechanisms: $\mathrm{OH}$ addition on aromatic or unsaturated groups, which result in radical adducts; hydrogen atom transfer; and single electron transfer. $^{21,22}$ For OBS, the double bond and benzene ring are the most likely attacked sites by $\mathrm{OH}$ radicals. Hence, in $\mathrm{UV} / \mathrm{H}_{2} \mathrm{O}_{2}$ system the $\mathrm{OH}$ radical can react with OBS through four possible routes: (I) $\mathrm{OH}$ addition on double bond to from an epoxy structure, (II) $\mathrm{OH}$ addition on benzene ring to form $\mathrm{OH}$ adducts, (III) electrophilic attack of $\mathrm{C}-\mathrm{F}$ bond at position 3 and 4 (C atoms are arbitrarily labelled, as shown in Fig. 4), (IV) electrophilic attack of $\mathrm{O}$ at position 6. For the addition reaction through Route I and Route II, the $\mathrm{OH}$ radical is added to the double bond, thus forming of a dihydroxy-alcohol. The addition reaction by $\mathrm{OH}$ addition on the benzene ring results in formation of two adducts, namely $\mathrm{C}_{15} \mathrm{H}_{6} \mathrm{~F}_{17} \mathrm{O}_{7} \mathrm{~S}^{-}$and $\mathrm{C}_{15} \mathrm{H}_{4} \mathrm{~F}_{17} \mathrm{O}_{5} \mathrm{~S}^{-}$. By elimination of a $\mathrm{H}_{2} \mathrm{O}$ molecule on $\mathrm{C} 3$ and $\mathrm{C} 4$ of $\mathrm{C}_{15} \mathrm{H}_{6} \mathrm{~F}_{17} \mathrm{O}_{7} \mathrm{~S}^{-}$, an epoxy group is formed $\left(\mathrm{C}_{15} \mathrm{H}_{4} \mathrm{~F}_{17} \mathrm{O}_{5} \mathrm{~S}^{-}\right)$. If the $\mathrm{CF}_{3}$ group at position 5 is substituted by $\mathrm{OH}$, then $\mathrm{C}_{14} \mathrm{H}_{5} \mathrm{~F}_{14} \mathrm{O}_{7} \mathrm{~S}^{-}$is formed. In the second step, the aromatic group of $\mathrm{C}_{14} \mathrm{H}_{5} \mathrm{~F}_{14} \mathrm{O}_{7} \mathrm{~S}^{-}$is rather quickly decomposed to form the stable $\mathrm{C}_{7} \mathrm{HF}_{14} \mathrm{O}^{-}$product, whose concentration increases continuously along $2 \mathrm{~h}$ reaction. The alcoholic group on $\mathrm{C} 2$ is further oxidized into ketone with simultaneous replacement of $\mathrm{F}$ at $\mathrm{C} 3$ and $\mathrm{C} 4$ by $\mathrm{OH}$ radicals to form $\mathrm{C}_{7} \mathrm{HF}_{12} \mathrm{O}_{3}{ }^{-}$.

Concerning the degradation of $\mathrm{C}_{7} \mathrm{HF}_{14} \mathrm{O}^{-}$, the $\mathrm{C}-\mathrm{C}$ bond is broken up at position 2 to form $\mathrm{C}_{4} \mathrm{~F}_{7} \mathrm{O}_{2}{ }^{-}$. Consequently, the two $\mathrm{C}-\mathrm{C}$ adjacent bonds (i.e. $\mathrm{C} 2-\mathrm{C} 3$ and $\mathrm{C} 2-\mathrm{C} 4$ ) are weakened due to the branched $\mathrm{CF}_{3}$ group. ${ }^{23,24}$ Jin and Zhang also found that branched PFOS shows higher degradability respect to the linear one. ${ }^{25}$ From this perspective, the branched structures in OBS increase its degradability respect to linear perfluoroalkyl compounds.

The $\mathrm{C}_{7} \mathrm{HF}_{12} \mathrm{O}_{3}{ }^{-}$is split into $\mathrm{C}_{4} \mathrm{HF}_{6} \mathrm{O}_{3}{ }^{-}$and $\mathrm{C}_{3} \mathrm{HF}_{6} \mathrm{O}_{2}{ }^{-}$by attack to the ketonic group; the carboxyl group on $\mathrm{C}_{4} \mathrm{HF}_{6} \mathrm{O}_{3}{ }^{-}$can also be cleaved to generate $\mathrm{C}_{3} \mathrm{HF}_{6} \mathrm{O}_{2}{ }^{-}$with further oxidation. On the other hand, the $\mathrm{F}$ atom on $\mathrm{C} 4$ of $\mathrm{C}_{4} \mathrm{~F}_{7} \mathrm{O}_{2}{ }^{-}$(generated from $\mathrm{C}_{7} \mathrm{HF}_{14} \mathrm{O}^{-}$) can also be replaced by $\mathrm{OH}$. The further mineralization occurs by cleavage of $\mathrm{CF}_{3}$ group on $\mathrm{C} 3$ to give $\mathrm{C}_{2} \mathrm{~F}_{3} \mathrm{O}_{2}{ }^{-}$(i.e. TFA). Although TFA is considered to be relatively stable in $\mathrm{UV} / \mathrm{H}_{2} \mathrm{O}_{2}$ system, ${ }^{20}$ we found its mineralization after prolonged time.

$\mathrm{OH}$ radical can difficultly break $\mathrm{C}-\mathrm{F}$ bonds owing to the high energy demand. However, for the branched fluorinated structure of OBS, there are two strong electron withdrawing $\mathrm{CF}_{3}$ groups on both $\mathrm{C} 3$ and $\mathrm{C} 4$ atoms, which reduce the electron density and consequently weaken the bond energy of $\mathrm{C}-\mathrm{F}$ on $\mathrm{C} 3$ and $\mathrm{C} 4$. This facilitates the substitution of $\mathrm{F}$ atom by $\mathrm{OH}$ on both carbons. Therefore, we hypothesize that the electrophilic substitution of $\mathrm{F}$ at $\mathrm{C} 3$ and $\mathrm{C} 4$ happens at the second step of Route II to form $\mathrm{C}_{15} \mathrm{H}_{6} \mathrm{~F}_{15} \mathrm{O}_{7} \mathrm{~S}^{-}$and also at the beginning of Route III to form $\mathrm{C}_{15} \mathrm{H}_{6} \mathrm{~F}_{15} \mathrm{O}_{6} \mathrm{~S}^{-}$. The further degradation proceeds by attack to the benzene ring, thus the $\mathrm{C}_{15} \mathrm{H}_{6} \mathrm{~F}_{15} \mathrm{O}_{7} \mathrm{~S}^{-}$ produced from the second step of Route II and Route III is decomposed to $\mathrm{C}_{10} \mathrm{H}_{2} \mathrm{~F}_{15} \mathrm{O}_{5}{ }^{-}$. The resulting $\mathrm{C}_{10} \mathrm{H}_{2} \mathrm{~F}_{15} \mathrm{O}_{5}{ }^{-}$is split into $\mathrm{C}_{7} \mathrm{HF}_{12} \mathrm{O}_{3}{ }^{-}$(or $\mathrm{C}_{3} \mathrm{HF}_{6} \mathrm{O}_{2}{ }^{-}$) and TFA by cleavage of the $\mathrm{C} 1=$ $\mathrm{C} 2$ bond. Then, the following degradation pathway of $\mathrm{C}_{7} \mathrm{HF}_{12} \mathrm{O}_{3}{ }^{-}$(or $\mathrm{C}_{4} \mathrm{HF}_{6} \mathrm{O}_{3}{ }^{-}$) and TFA is the same of Route I.

In Route IV, the electrophilic attack takes place at $\mathrm{O} 6$ atom (Fig. 4), and OBS is split into $\mathrm{C}_{9} \mathrm{~F}_{17} \mathrm{O}^{-}(\mathrm{m} / \mathrm{z}=446.9)$ and PSA. No increase of PSA was observed during the reaction due to its fast degradation kinetic in $\mathrm{UV} / \mathrm{H}_{2} \mathrm{O}_{2}$ system (Fig. 5). This was totally different from that in UV system (see Section 3.4). For the further degradation of $\mathrm{C}_{9} \mathrm{~F}_{17} \mathrm{O}^{-}$, it follows the same procedure like $\mathrm{C}_{10} \mathrm{H}_{2} \mathrm{~F}_{15} \mathrm{O}_{5}{ }^{-}$by breakage of $\mathrm{C}=\mathrm{C}$ bond, and the resulting $\mathrm{C}_{7} \mathrm{HF}_{12} \mathrm{O}_{3}{ }^{-}$(or $\mathrm{C}_{4} \mathrm{HF}_{6} \mathrm{O}_{3}{ }^{-}$) and TFA can be decomposed stepwise in the same way above-mentioned.

\subsection{Degradation products and proposed pathway of OBS in UV system}

As constituent of sunlight, ultraviolet light plays an important role for transformation of organic pollutants in the environment. 


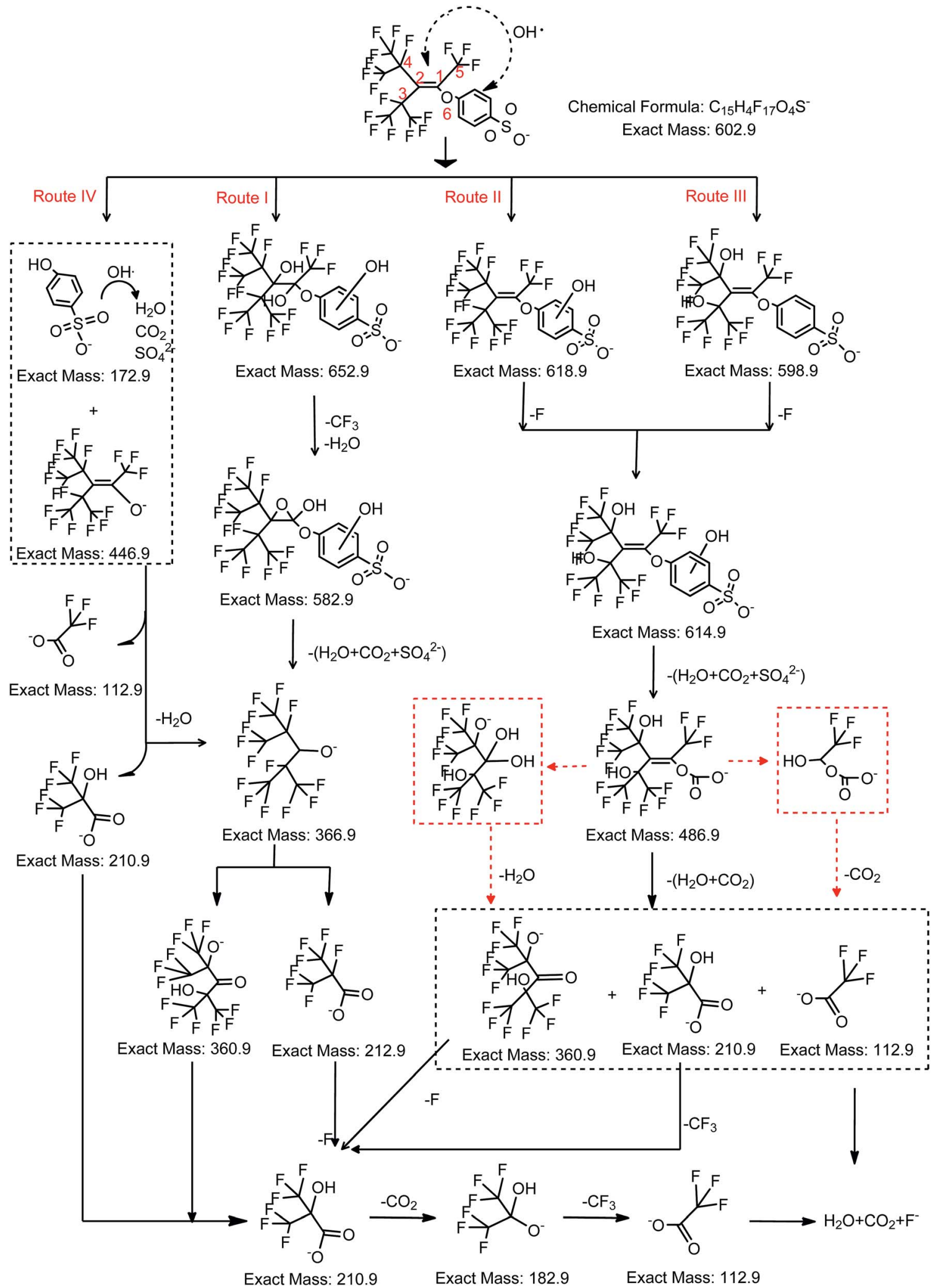

Fig. 4 Proposed degradation pathway of OBS under $\mathrm{UV} / \mathrm{H}_{2} \mathrm{O}_{2}$.

The sunlight that reaches the earth has its maximum wavelength at $365 \mathrm{~nm} .{ }^{26}$ Therefore, the photochemical behavior of OBS was firstly tested under $365 \mathrm{~nm}$ UV. However, no significant elimination was found under such light (Fig. S3†). This indicates that the decomposition of OBS in the natural environment by sunlight is conceivably quite slow. Conversely, as showed in Fig. 2a, we found that OBS can be easily decomposed under $254 \mathrm{~nm} \mathrm{UV}$, through the mechanism described hereafter. 


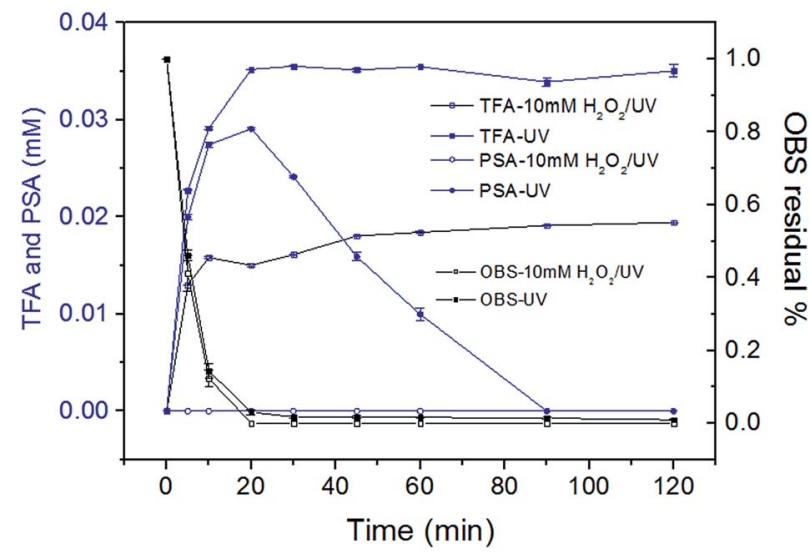

Fig. 5 Variation of PSA and TFA in UV and UV/ $\mathrm{H}_{2} \mathrm{O}_{2}$ system during $2 \mathrm{~h}$ reaction.

OBS molecule possesses an aromatic ring that acts as a unit to initiate photosensitized reactions with reactive oxidative species (ROS), which may be present in the reaction medium..$^{27,28}$ In order to identify such ROS under UV (254 nm) light, electron spin resonance analysis was performed. As showed in Fig. 6, singlet state oxygen $\left({ }^{1} \mathrm{O}_{2}\right)$ was generated in OBS aqueous solution by irradiation, but no appreciable $\mathrm{OH}$ radical and superoxide anion signal $\left(\mathrm{O}_{2}{ }^{-}\right)$were found. The generation of singlet oxygen decreases gradually due to discontinuous introduction of oxygen into the system. To further corroborate identification of the dominant ROS, inhibition experiment was also conducted. Only quenching of ${ }^{1} \mathrm{O}_{2}$ and OBS excited triplet state (OBS*) by sorbic acid addition could substantially lower the removal efficiency (Fig. S4 $\dagger$ ). These results highlight that, in the UV system, two mechanisms are responsible for the OBS degradation: (1) direct photolysis, where OBS is firstly excited to the triplet state (T1) by UV light and, then, split at the weaker bond (while the excited electrons return to the ground state); (2) oxidation of OBS by ${ }^{1} \mathrm{O}_{2}$. The simplified reaction scheme of the overall degradation process is described by eqn (2)-(5). ${ }^{29-31}$

$$
\text { OBS } \stackrel{h v}{\rightarrow} \text { OBS*(triplet state). }
$$

$$
\begin{gathered}
\text { OBS } *(\mathrm{~T} 1) \rightarrow \text { products. } \\
\text { OBS } *(\mathrm{~T} 1)+{ }^{3} \mathrm{O}_{2} \rightarrow \mathrm{OBS}+{ }^{1} \mathrm{O}_{2} . \\
\mathrm{OBS}+{ }^{1} \mathrm{O}_{2} \rightarrow \text { products. }
\end{gathered}
$$

For the sake of clarity, the two mechanisms (viz. direct photolysis and oxidation by ${ }^{1} \mathrm{O}_{2}$ ) are later proposed separately.

Some of the products and intermediates of OBS degradation in UV system are the same as those detected in the $\mathrm{UV} / \mathrm{H}_{2} \mathrm{O}_{2}$ system. Intermediates are $\mathrm{C}_{15} \mathrm{H}_{4} \mathrm{~F}_{17} \mathrm{O}_{5} \mathrm{~S}^{-}(\mathrm{m} / \mathrm{z}=618.9)$ and $\mathrm{C}_{15} \mathrm{H}_{6} \mathrm{~F}_{15} \mathrm{O}_{6} \mathrm{~S}^{-}(\mathrm{m} / \mathrm{z}=598.9)$, which were eliminated stepwise within the $2 \mathrm{~h}$ treatment. $\mathrm{C}_{7} \mathrm{HF}_{14} \mathrm{O}^{-}(\mathrm{m} / z=366.9), \mathrm{C}_{7} \mathrm{HF}_{12} \mathrm{O}_{3}{ }^{-}$ $(m / z=360.9), \mathrm{C}_{4} \mathrm{~F}_{7} \mathrm{O}_{2}{ }^{-}(m / z=212.9), \mathrm{C}_{4} \mathrm{HF}_{6} \mathrm{O}_{3}{ }^{-}(\mathrm{m} / z=210.9)$, $\mathrm{C}_{3} \mathrm{HF}_{6} \mathrm{O}_{2}{ }^{-}(m / z=182.9)$ and $\mathrm{C}_{2} \mathrm{~F}_{3} \mathrm{O}_{2}{ }^{-}(\mathrm{m} / z=112.9)$ were formed as stable degradation products. In addition, several new products were found, that is, $\mathrm{C}_{15} \mathrm{H}_{4} \mathrm{~F}_{17} \mathrm{O}_{5} \mathrm{~S}^{-}(\mathrm{m} / \mathrm{z}=618.9)$ and its isomer (Fig. 7 and 8), $\mathrm{C}_{14} \mathrm{H}_{5} \mathrm{~F}_{14} \mathrm{O}_{7} \mathrm{~S}^{-}(\mathrm{m} / \mathrm{z}=$ 582.9), $\mathrm{C}_{14} \mathrm{H}_{6} \mathrm{~F}_{13} \mathrm{O}_{7} \mathrm{~S}^{-} \quad(m / z=564.9), \quad \mathrm{C}_{7} \mathrm{H}_{5} \mathrm{O}_{11} \mathrm{~S}^{-}(\mathrm{m} / \mathrm{z}=296.9)$, $\mathrm{C}_{7} \mathrm{H}_{5} \mathrm{O}_{10} \mathrm{~S}^{-}(\mathrm{m} / \mathrm{z}=280.9), \mathrm{C}_{6} \mathrm{H}_{5} \mathrm{O}_{8} \mathrm{~S}^{-} \quad(\mathrm{m} / \mathrm{z}=236.9)$, and $\mathrm{C}_{6} \mathrm{H}_{5} \mathrm{O}_{4} \mathrm{~S}^{-}(\mathrm{m} / z=172.9)$. Their extracted compound spectra and the corresponding structures were shown in Fig. S5. $\dagger$

3.4.1 Direct photolysis. The direct photolysis (Fig. 7) was initiated by excitation of ground state OBS to triplet state (T1). As the excited OBS* (T1) returns to the ground state, the molecule weaker bond likely breaks up. Conceivably, OBS is firstly split up at the double bond to produce two carbanions, $\mathrm{C}_{7} \mathrm{~F}_{14}{ }^{2 \cdot-}$ and $\mathrm{C}_{8} \mathrm{H}_{4} \mathrm{~F}_{3} \mathrm{O}_{4} \mathrm{~S}^{2 \cdot}$. Then, $\mathrm{C}_{7} \mathrm{~F}_{14}{ }^{2 \cdot-}$ is quickly hydrolyzed to $\mathrm{C}_{7} \mathrm{HF}_{14} \mathrm{O}^{-}$, while $\mathrm{C}_{8} \mathrm{H}_{4} \mathrm{~F}_{3} \mathrm{O}_{4} \mathrm{~S}^{2 \cdot-}$ is cleaved at position 1 due to the electron-withdrawing effect of $\mathrm{CF}_{3}$ and $\mathrm{O}-\mathrm{Ar}$ groups. Two possible pathways for disintegration of $\mathrm{C}_{8} \mathrm{H}_{4} \mathrm{~F}_{3} \mathrm{O}_{4} \mathrm{~S}^{2 \cdot-}$ are proposed. The C1-O6 bond breaks up to form $\mathrm{C}_{6} \mathrm{H}_{5} \mathrm{O}_{4} \mathrm{~S}^{-}$(PSA) and TFA (Type I in Fig. 7). Alternatively, $\mathrm{CF}_{3}$ is probably split away from $\mathrm{C}_{8} \mathrm{H}_{4} \mathrm{~F}_{3} \mathrm{O}_{4} \mathrm{~S}^{2 \cdot-}$ to generate $\mathrm{C}_{7} \mathrm{H}_{5} \mathrm{O}_{6} \mathrm{~S}^{-}$(Type II). Nevertheless, $\mathrm{C}_{7} \mathrm{H}_{5} \mathrm{O}_{6} \mathrm{~S}^{-}$could not be detected because of its fast reaction with ${ }^{1} \mathrm{O}_{2}$ (Fig. 8) to form further adducts. Pochon et al. proposed that excited triplet state reacts with $\mathrm{H}_{2} \mathrm{O}$ by an "hydroxylating process" during the photochemical oxidation of water by 2-methyl-1,4-benzoquinone, which ends in $\mathrm{OH}$ addition. $^{32}$ Since PSA has a wide and strong absorption between 200-300 $\mathrm{nm}$ (Fig. S6†), we presume that it can also be excited to triplet state (PSA*) and generate hydroxylated intermediates with $\mathrm{H}_{2} \mathrm{O}$ (following the Type I pathway). Actually, the all-hydroxylated product (i.e. 2,3,4,5,6-pentahydroxyphenol sulfonic acid, $m / z=236.9$ ) was identified by its mass spectrum. Such finding suggests that hydroxylation continues until complete substitution of benzene ring, thus forming the above-mentioned compound, which is a stable product (within $2 \mathrm{~h}$ reaction). Concerning the Type II pathway, it is very likely that 4-(carboxyoxy)phenol sulfonic acid possess similar UV-vis adsorption band range to PSA because of its analogous aromatic structure. Hence, a similar oxidizing process by hydroxylating intermediates is followed by triplet state 4(carboxyoxy)phenol sulfonic acid and $\mathrm{H}_{2} \mathrm{O}$. In the end, the allhydroxylated product, i.e. 4-(carboxyoxy)-2,3,5,6tetrahydroxyphenol sulfonic acid (identified by its mass spectrum, $m / z=280.9)$, is formed. Interestingly, a peroxide $(\mathrm{m} / z=$ 296.9) was also detected among final products of 4 -(carboxyoxy)phenol sulfonic acid hydroxylation. In spite of its known instability, the peroxy moiety may be stabilized by resonance with carboxyl group. This might also explain why no peroxyproducts from PSA (without carboxyl moiety) were found. Kimura and Ogata found that $-\mathrm{SO}_{3}{ }^{-}$can be cleaved from $\mathrm{R}-\mathrm{Ar}-$ $\mathrm{SO}_{3}{ }^{-}$group by UV irradiation, ${ }^{33}$ so such desulfonation process might also occur in this system for PSA and 4-(carboxyoxy) phenol sulfonic acid to produce $\mathrm{SO}_{4}{ }^{2-}$.

3.4.2 Singlet oxygen-dominated oxidation. The oxidation pathway of OBS in UV system dominated by ${ }^{1} \mathrm{O}_{2}$ (Fig. 8) comprises four routes, differentiated by the triggering reaction of OBS degradation: (A) cleavage of the $\mathrm{CF}_{3}$ bound to $\mathrm{C} 1$, (B) substitution of $\mathrm{F}$ atoms on $\mathrm{C} 3$ and $\mathrm{C} 4$, (C) formation of hydroperoxy adduct, and (D) formation of hydroxyl adduct. 


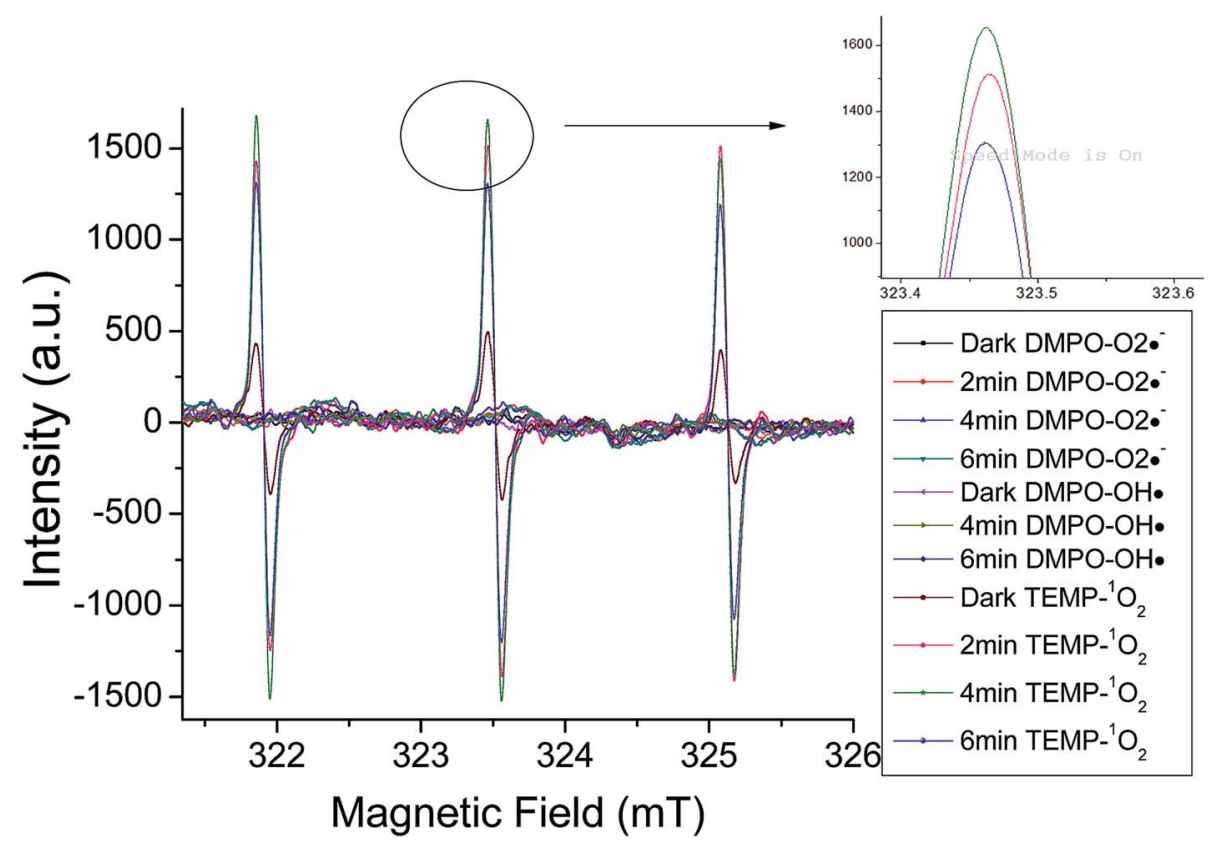

Fig. 6 ESR spectra of TEMP- ${ }^{1} \mathrm{O}_{2}$ and $\mathrm{DMPO}-\mathrm{OH}^{\cdot}$ in $\mathrm{OBS}$ aqueous solution and DMPO-O${ }^{\cdot-}$ in OBS methanol solution.

With regard to Route $\mathrm{A}$, the $\mathrm{CF}_{3}$ is probably split away from the molecule by homolysis of excited OBS or ${ }^{1} \mathrm{O}_{2}$ attack to form $\mathrm{C}_{14} \mathrm{H}_{5} \mathrm{~F}_{14} \mathrm{O}_{5} \mathrm{~S}^{-}$. Soon after, the double bond on $\mathrm{C}_{14} \mathrm{H}_{5} \mathrm{~F}_{14} \mathrm{O}_{5} \mathrm{~S}^{-}$ is rapidly oxidized by ${ }^{1} \mathrm{O}_{2}$ to generate dioxetane compound $\left(\mathrm{C}_{14} \mathrm{H}_{5} \mathrm{~F}_{14} \mathrm{O}_{7} \mathrm{~S}^{-}, m / z=582.9\right)$, which decomposes at the carbonyl group. ${ }^{34}$ At the same time, the $\mathrm{F}$ atom at $\mathrm{C} 3$ or $\mathrm{C} 4$ detaches to produce $\mathrm{C}_{14} \mathrm{H}_{6} \mathrm{~F}_{13} \mathrm{O}_{7} \mathrm{~S}^{-}$, so inducing subsequent rupturing of $\mathrm{C} 1=\mathrm{C} 2$ bond to generate an aromatic compounds and a fluorinated fragment $\left(\mathrm{C}_{7} \mathrm{HF}_{12} \mathrm{O}_{3}{ }^{-}\right)$. On the one hand, the benzenic compound is oxidized stepwise by ${ }^{1} \mathrm{O}_{2}$ to small acid molecules such as maleic acid and fumaric acid, and finally mineralized to some extent. ${ }^{35,36}$ However, maleic acid or any other carboxylic acid was not detected because the reaction solution $\mathrm{pH}$ decreased to around 3.3, thus inhibiting carboxyl acid dissociation (e.g. fumaric acid with $\mathrm{pKa}=3.15$, acetic acid with pKa $=4.79)$. On the other hand, $\mathrm{C}_{7} \mathrm{HF}_{12} \mathrm{O}_{3}{ }^{-}$is further attacked by ${ }^{1} \mathrm{O}_{2}$ to produce $\mathrm{C}_{4} \mathrm{HF}_{6} \mathrm{O}_{3}{ }^{-}$or $\mathrm{C}_{3} \mathrm{HF}_{6} \mathrm{O}_{2}{ }^{-}$, and they are also defluorinated to TFA step by step following a similar pathway to $\mathrm{UV} / \mathrm{H}_{2} \mathrm{O}_{2}$ system. For Route $\mathrm{B}$, the $\mathrm{F}$ atom linked to $\mathrm{C} 3$ or $\mathrm{C} 4$ atom is firstly substituted by $\mathrm{OH}$ to form $\mathrm{C}_{15} \mathrm{H}_{6} \mathrm{~F}_{15} \mathrm{O}_{6} \mathrm{~S}^{-}$, and subsequently, the double bond is cleaved by ${ }^{1} \mathrm{O}_{2}$. Then, the carbanion (C7F14 ${ }^{2 \cdot-}$ ) is hydrolyzed to form $\mathrm{C}_{7} \mathrm{HF}_{14} \mathrm{O}^{-}$. This latter fragment follows the above-explained defluorination mechanism of Route A. Meanwhile, the aromatic moiety would be fractured to TFA by ${ }^{1} \mathrm{O}_{2}$; the $\mathrm{C}_{7} \mathrm{HF}_{14} \mathrm{O}^{-}$undergoes the same oxidation process described for Route A. Concerning Route C and D, the two isomers $(\mathrm{m} / \mathrm{z}=$ 618.9, but with different retention times) are conceivably produced according to previous findings of Derosa and Crutchley. ${ }^{28}$ The authors concluded that ${ }^{1} \mathrm{O}_{2}$ can oxidize phenol to hydroperoxides, followed by dehydration to quinone. Likewise, we propose a quinonic specie at the beginning of Route $\mathrm{C}$. Besides, the triplet-state OBS would also react with water by hydroxylating process to give hydroxyl adducts, ${ }^{32}$ which is the second isomer (with $\mathrm{m} / \mathrm{z}=618.9$ ) we identified that initiates Route D. Both isomers are decomposed following the same mechanisms proposed above.

\subsection{Comparison of degradation mechanism under UV and $\mathrm{UV} / \mathrm{H}_{2} \mathrm{O}_{2}$}

The aromatic group, the double bond and $\mathrm{CF}_{3}$ groups in the branched perfluorinated moiety make OBS easier to be degraded compared to PFOS. Still, the defluorination process is not complete, and stable degradation products are formed in both systems. Therefore, longer reaction time and combination of other techniques (e.g. catalytic oxidation) would obtain a satisfactory degradation and possibly entire mineralization.

In UV system, the generation of TFA and PSA reached the maxima simultaneously until 20 min when $>96 \%$ OBS was decomposed (Fig. 5). TFA was levelled off at prolonged time, while PSA was further degraded (as described in Section 3.6). OBS decomposition rate by UV was sensibly lower than that in $\mathrm{UV} / \mathrm{H}_{2} \mathrm{O}_{2}$. This is reasonably due, in the first instance, to the ${ }^{1} \mathrm{O}_{2}$ low concentration (compared to $\mathrm{OH}$ radicals generated from $10 \mathrm{mM} \mathrm{H}_{2} \mathrm{O}_{2}$ ), determined by low $\mathrm{O}_{2}$ amount in the system (no forced aeration was adopted in the experiments). Secondly, the complex degradation products in UV system could quench OBS*, thus slowing down the elimination of OBS. Finally, the acidic environment ( $\mathrm{pH}=3.3$ after reaction) probably inhibited OBS photolysis. ${ }^{36}$

In the $\mathrm{UV} / \mathrm{H}_{2} \mathrm{O}_{2}$ system, no detectable amount of PSA was generated during reaction (Fig. 5). So the PSA was decomposed effectively to entirely release sulfate ions. The degradation of PSA in both systems were tested (Fig. S7 $†$ ). The results showed that almost $100 \%$ of sulfate ion was recovered in $\mathrm{UV} / \mathrm{H}_{2} \mathrm{O}_{2}$ 


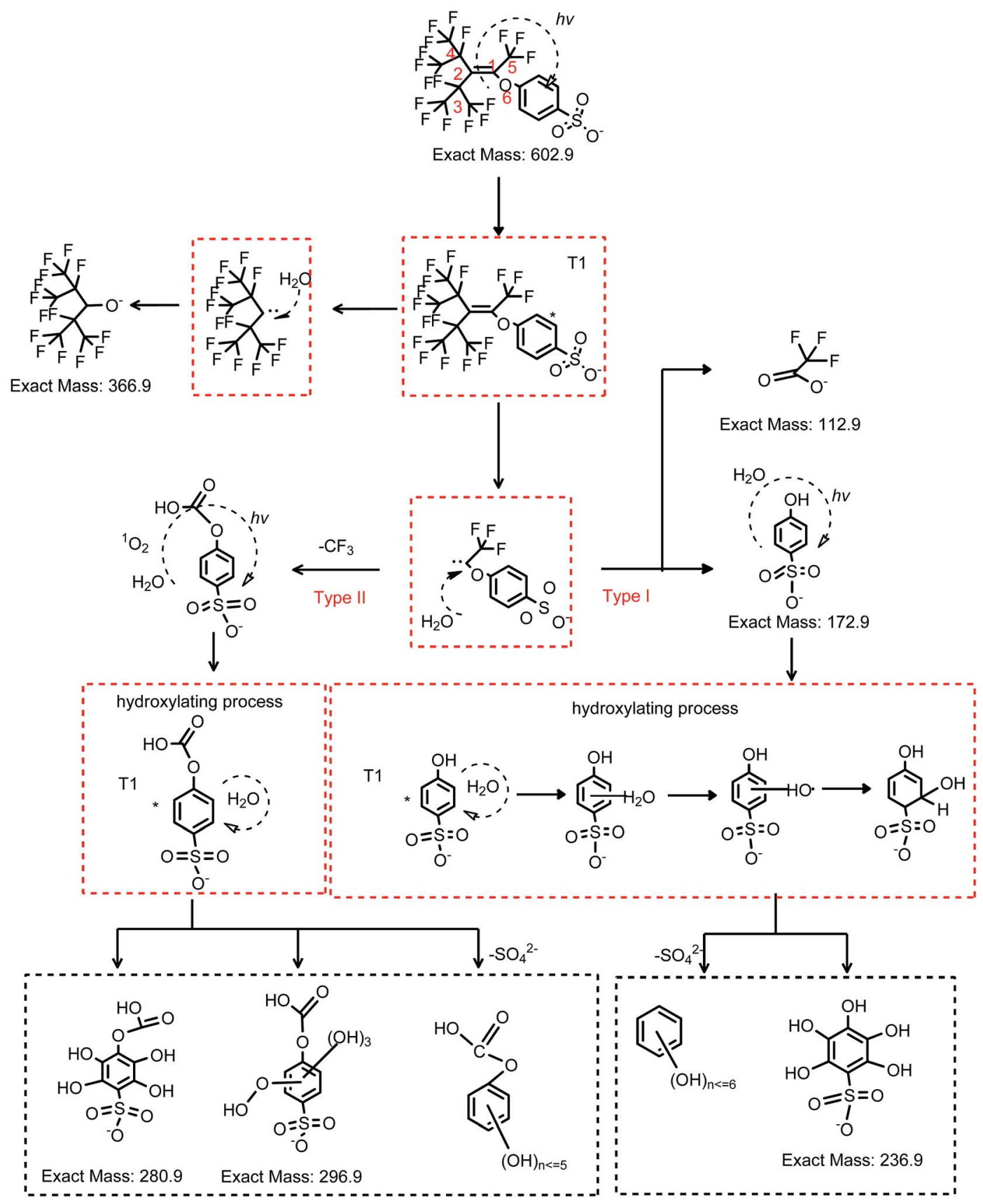

Fig. 7 Proposed degradation pathway of OBS under UV dominated by direct photolysis.

system and much less in UV system. With regard to the second degradation product that was investigated in detail, i.e. TFA, its generation did not reach the theoretical maximum when OBS was totally decomposed, but it kept gradually increasing until $60 \mathrm{~min}$, and then its concentration remained stable. The reason is that after 60 min reaction, production and degradation rates of TFA were in equilibrium. The concentration of TFA after $2 \mathrm{~h}$ in $\mathrm{UV} / \mathrm{H}_{2} \mathrm{O}_{2}$ system was considerably lower than that in $\mathrm{UV}$ system. This is probably due to partial mineralization of $\mathrm{CF}_{3}$ group of aromatic moiety linked to $\mathrm{C} 1$ that could not generate TFA.
The defluorination efficiency in $\mathrm{UV} / \mathrm{H}_{2} \mathrm{O}_{2}$ system was not much higher compared to the UV treatment indicating that a similar amount of fluorinated degradation products still existed. However, PSA and any aromatic products, as well as TFA, showed considerable lower concentrations at the end of the treatment compared to the sole UV degradation. In terms of safety of a possible AOP treatment process, the aromatic compounds might be more toxic, so their higher concentration in water under UV light should be taken into account. ${ }^{37}$ TFA also possesses some toxicity (for instance, its oral $\mathrm{LC}_{50}$ for rat is $\left.200 \mathrm{mg} \mathrm{kg}^{-1} \mathrm{bw}\right){ }^{38}$ Hence, the $\mathrm{UV} / \mathrm{H}_{2} \mathrm{O}_{2}$ is a safer treatment for degrading OBS. 


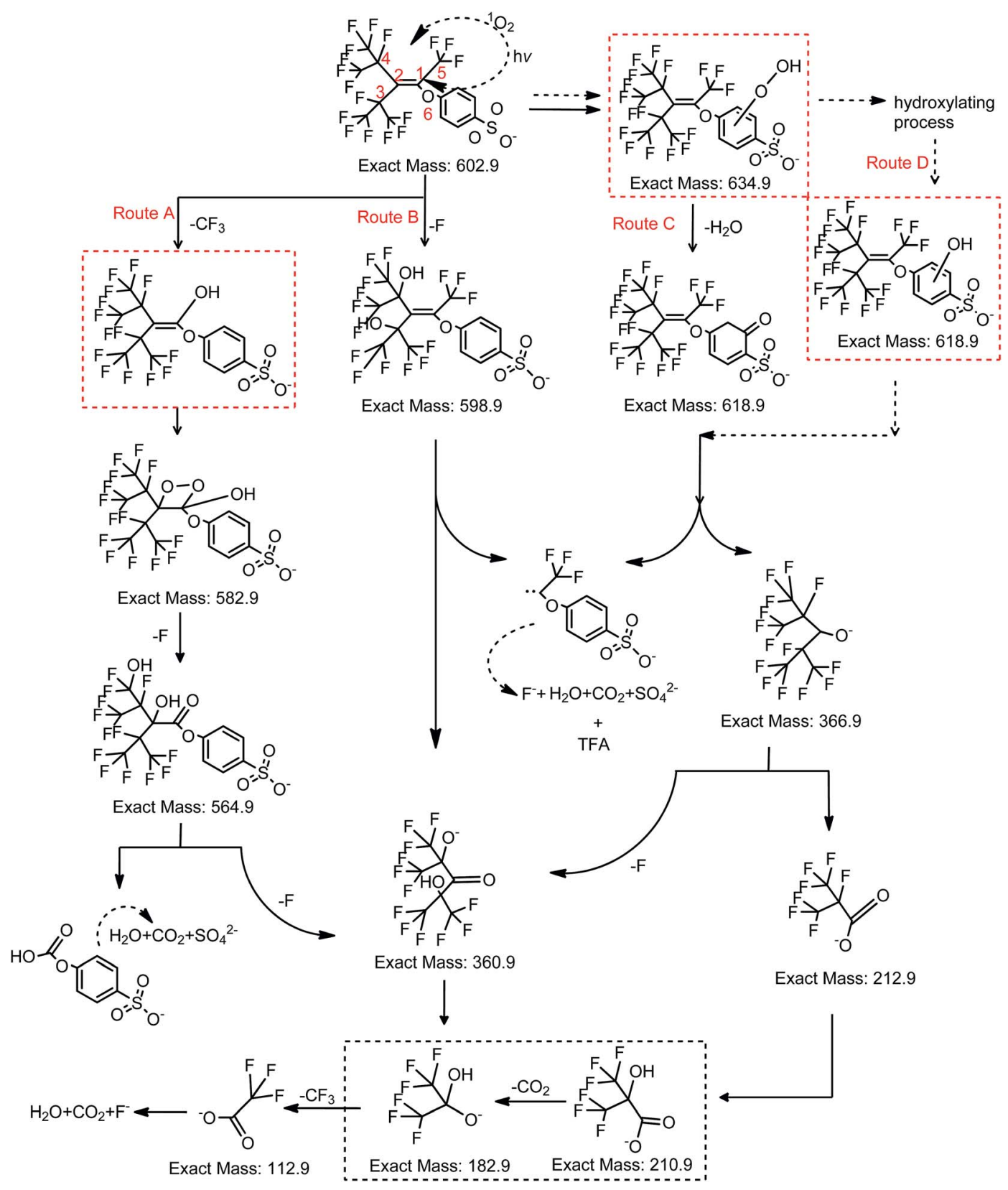

Fig. 8 Proposed degradation pathway of OBS under UV dominated by ${ }^{1} \mathrm{O}_{2}$.

\section{Conclusions}

OBS, a widely used polyfluorinated PFOS-alternative in China, was for the first time assessed for biotic and abiotic degradability. Closed bottle tests showed a strong recalcitrance of OBS to any biological transformation in the short period $(28 \mathrm{~d})$. Hence, such surfactant, like all the other PFASs, is a non-readily biodegradable chemical. Nonetheless, our investigation on abiotic degradability under AOP conditions highlighted that, differently from the majority of fluorinated compounds, OBS is degradable in substantial manner.

OBS could be decomposed under UV (254 nm) and even better in $\mathrm{UV} / \mathrm{H}_{2} \mathrm{O}_{2}$. However, under both conditions complex by- products were formed and less than $20 \%$ of fluorine was mineralized. The $\mathrm{UV} / \mathrm{H}_{2} \mathrm{O}_{2}$ showed a more promising degradation performance, which might be combined with other technologies to detoxify OBS effectively. In addition, OBS was not degraded under $365 \mathrm{~nm}$ UV irradiation (main UV component of sunlight reaching the earth). Therefore, the photolysis of OBS in natural environment might be rather slow. On contrary, the efficient degradation in $\mathrm{UV} / \mathrm{H}_{2} \mathrm{O}_{2}$ suggests that OBS may be affected by long term biological transformations.

\section{Conflicts of interest}

There are no conflicts to declare. 


\section{Acknowledgements}

This research was financially supported by the National Natural Science Fund of China (No.21477060) and Tsinghua University Initiative Scientific Research Program (20131089251).

\section{References}

1 V. Ciccotelli, M. C. Abete and S. Squadrone, Food Control, 2016, 59, 46-52.

2 T. Frömel and T. P. Knepper, Rev. Environ. Contam. Toxicol., 2010, 208, 161-177.

3 T. M. Boudreau, C. J. Wilson, W. J. Cheong, P. K. Sibley, S. A. Mabury, D. C. G. Muir and K. R. Solomon, Environ. Toxicol. Chem., 2003, 22, 2739-2745.

4 B. O. Clarke and S. R. Smith, Environ. Int., 2011, 37, 226-247.

5 J. P. Giesy and K. Kannan, Environ. Sci. Technol., 2001, 35, 1339-1342.

6 S. K. Ritter, Chem. Eng. News, 2010, 88, 12-17.

7 A. Blum, S. A. Balan, M. Scheringer, X. Trier, G. Goldenman, I. T. Cousins, M. Diamond, T. Fletcher, C. Higgins, A. E. Lindeman, G. Peaslee, P. Voogt, Z. Wang and R. Weber, Environ. Health Perspect., 2015, 123, A107-A111.

8 Z. Wang, J. C. DeWitt, C. P. Higgins and I. T. Cousins, Environ. Sci. Technol., 2017, 51, 2508-2518.

9 L. Zhao, P. K. Mccausland and P. W. Folsom, Chemosphere, 2013, 92, 464-470.

10 J. C. W. Lam, J. Lyu and K. Y. Kwok, Environ. Sci. Technol., 2016, 50, 6728-6734.

11 Q. Zhang, W. Liu and Q. Niu, Toxicol. Res., 2014, 5, 539-546.

12 H. Viberg, I. Lee and P. Eriksson, Toxicology, 2013, 304, 185191.

13 http://www.sh3f.com/product_view.asp?id=34\&mc=e851a032 67f01c172e9c1e204ea16525f766fa44e1ed0ff6.

14 L. Chen, H. Shi, H. Wu and J. Xiang, Colloids Surf., A, 2011, 384, 331-336.

15 H. K. Wu, J. Q. Zhong, H. M. Shen and H. X. Shi, J. Fluorine Chem., 2013, 156, 5-8.

16 C. Li, Master Dissertation, Qingdao Technological University, 2016.

17 H. F. Schröder and R. J. W. Meesters, J. Chromatogr. A, 2005, 1082, 110-119.

18 N. Quinete, F. Orata, A. Maes, M. Gehron, K. H. Bauer, I. Moreira and R. D. Wilken, Arch. Environ. Contam. Toxicol., 2010, 59, 20-30.
19 S. Wang, J. Huang, Y. Yang, Y. Hui, Y. Ge, T. Larssen, G. Yu, S. Deng, B. Wang and C. Harman, Environ. Sci. Technol., 2013, 47, 10163-10170.

20 X. Yang, J. Huang, K. Zhang, G. Yu, S. Deng and B. Wang, Environ. Sci. Pollut. Res., 2014, 21, 4634-4642.

21 G. H. Naik, K. I. Priyadarsini, A. K. Maity and H. Mohan, J. Phys. Chem. A, 2005, 109, 2062-2068.

22 A. Galano and J. R. Alvarez-Idaboy, Org. Lett., 2009, 11, 51145117.

23 V. Tortelli, C. Tonelli and C. Corvaja, J. Fluorine Chem., 1993, 60, 165-174.

24 C. Tonelli and V. Tortelli, J. Fluorine Chem., 1994, 67, 125128.

25 L. Jin and P. Zhang, Chem. Eng. J., 2015, 280, 241-247.

26 X. Zhao, T. Toyooka and Y. Ibuki, Sci. Total Environ., 2013, 458-460, 54-62.

27 M. S. Baptista, J. Cadet, D. P. Mascio, A. A. Ghogare, A. Greer, M. R. Hamblin, C. Lorente, S. C. Nunez, M. S. Ribeiro, A. H. Thomas, M. Vignoni and T. M. Yoshimura, Photochem. Photobiol., 2017, 93, 912-919.

28 M. C. Derosa and R. J. Crutchley, Coordin. Chem. Rev., 2002, 233-234, 351-371.

29 C. S. Foote, Acc. Chem. Res., 1968, 1, 104-110.

30 K. Li and J. L. Ferry, Environ. Sci. Technol., 2003, 37, 48944900.

31 Y. Chen, C. Hu, J. Qu and M. Yang, J. Photochem. Photobiol., A, 2008, 197, 81-87.

32 A. Pochon, P. P. Vaughan, D. Q. Gan, P. Vath, N. V. Blough and D. E. Falvey, J. Phys. Chem. A, 2002, 106, 2889-2894.

33 M. Kimura and Y. Ogata, Bull. Chem. Soc. Jpn., 2006, 56, 471473.

34 S. Mazur and C. S. Foote, J. Am. Chem. Soc., 2002, 92, 32253226.

35 X. Tian, P. Gao, Y. Nie, C. Yang, Z. Zhou, Y. Li and Y. Wang, Chem. Commun., 2017, 53, 6589-6592.

36 J. S. Miller, Rose bengal-sensitized photooxidation of 2chlorophenol in water using solar simulated light, Water Res., 2005, 39, 412-422.

37 S. Weng, J. Y. Yang, Y. H. Li and E. R. Blatchley 3rd, Sci. Total Environ., 2017, 599-600, 94-97.

38 US National Library of Medicine, trifluoroacetic acid, 76-051, animal toxicity studies, https:/toxnet.nlm.nih.gov/cgibin/sis/search2/f?./temp/ eE5qWO:1. 